\title{
Prevalence and Intensity of Schistosomiasis in Communities around Water Reservoirs in Malawi
}

Austin H.N Mtethiwa ${ }^{1,2^{*}}$, Jared Bakuza² and Gamba Nkwengulila ${ }^{3}$

${ }^{1}$ Lilongwe University of Agriculture and Natural Resources (LUANAR), Bunda College Campus, Lilongwe, Malawi

${ }^{2}$ Dar es Salaam University College of Education, Department of Biological Sciences, Dar es Salaam, Tanzania

${ }^{3}$ University of Dar es Salaam, Department of Zoology and Wildlife Conservation, Dar es Salaam, Tanzania

\section{Abstract}

Although schistosomiasis is endemic in Malawi, its epidemiology at water reservoir communities is not known. However, there are more than 750 water reservoirs spread throughout the country, providing water for various activities. The present study was conducted to determine schistosomiasis infection at reservoir communities in Malawi.

Methods: This was across sectional study conducted during the rainy and dry seasons at three water reservoir communities. A total of 1594 individuals aged from 1 to 78 years from $1-2 \mathrm{~km},>2-5 \mathrm{~km}$ and $5 \mathrm{~km}$ away from the reservoir were randomly selected and enrolled into the study. They provided stool and urine samples which were examined for Schistosoma eggs using Kato-Katz and sedimentation methods, respectively.

Results: An overall prevalence of $47.4 \%$ was found with $51.2 \%$ for S. haematobium and $9.5 \%$ for $S$. mansoni. Prevalence was significantly higher during the dry season (58.5\%) than the rainy season $(36.6 \%)(P=0.01)$. Prevalence was significantly higher in communities living $0-2 \mathrm{~km}$ away from the reservoir than in those living $>5 \mathrm{~km}$ away $(P=0.00)$. Prevalence of $S$. haematobium was significantly different higher at Mlala reservoir than at Ukonde and Njala reservoirs $(P=0.043)$. Prevalence of $S$. Mansoni was significantly higher at Ukonde reservoir than at Mlala and Njala reservoirs $(P=0.037)$. Prevalence among different age groups was not significantly different $(P=0.29)$. Age group of 6-15 years had significantly higher infection intensity, in both $S$. mansoni $(129 \pm 3.6 \mathrm{epg})$ and $S$. haematobium $(63.3 \pm 2.3 \mathrm{eggs} / 10 \mathrm{ml}$ of urine), than the other age groups.

Conclusion: Water reservoirs are infested with Schistosoma cercariae and the communities are at risk. The closer to the reservoir, the higher the chances of being infected. We recommend annual MDA, since the prevalence found is within the $\geq 50 \%$ WHO recommended threshold for MDA. We also recommend a health education to the communities on transmission and prevention of schistosomiasis.

Keywords: Schistosomiasis; Prevalence; Infection intensity; Water reservoirs

\section{Introduction}

Schistosomiasis is the third devastating tropical disease after malaria and helminthiasis, in terms of number of people to which it causes morbidity [1]. Humans acquire schistosomiasis through contact with cercariae infested freshwaters. The disease is endemic in 78 countries with an estimated 779 million people being at risk of contracting it [2]. Of this number, 106 million live in irrigation schemes or in close proximity to large water reservoirs [3]. Worldwide, about 280 million people are infected and over $90 \%$ of these live in Sub-Saharan Africa. The disease causes about 300,000 deaths in Africa only and about 150,000 of these deaths occur due to urogenital schistosomiasis [1]. Prevalence of the disease depends on the prevailing ecological, demographic, as well as socioeconomic characteristics of the society [4]. As such, documentation of the correlation between prevalence, intensity, demographic and ecological characteristics are useful input in designing a successful control measure. In Malawi, both urogenital and intestinal schistosomiasis exists. Localised studies over the years have shown spatially varying prevalence [5]. Current prevalence, as reported by the National Schistosomiasis Control Programme, stands at $40-50 \%$ [6]. However, a national study on the disease by Bowie, Purcell [7] reported a national prevalence of $6.9 \%$. Furthermore, localised studies in Blantyre and Chikhwawa found a S. haematobium prevalence of $10.4 \%$ and $14.2 \%$, respectively [5]. Other studies in Phalombe and along the shore areas of Lake Malawi reported a prevalence of about $94 \%$ in school aged children [8]. Consequently, studies on schistosomiasis in Malawi have been either conducted along Lake Malawi shores or concentrated in same places only $[9,10]$. This approach has resulted in leaving out all potential endemic areas, which include water reservoirs that serve a large proportion of the country's population. In Malawi, there are about 750 water reservoirs, with only 7 large dams mainly for municipal water supply [11]. Furthermore, the approach has rendered schistosomiasis information fragmented such that it difficult to make a correct conclusion on the distribution and transmission of the disease in Malawi [9]. The present study was conducted to investigate the role of water reservoirs in transmission and prevalence of schistosomiasis in Malawi to provide and improve knowledge of schistosomiasis in Malawi.

\section{Materials and Methods}

\section{Ethical clearance}

The research protocol was reviewed and approved by the College of Medicine Research and Ethics Committee (COMREC) in Malawi and certified under certificate no P.11/13/1496. Literate participants were

*Corresponding author: Austin H.N Mtethiwa, Lilongwe University of Agriculture and Natural Resources (LUANAR), P.O. Box 219, Lilongwe, Malawi, Tel: 265999662845; E-mail: amtethiwa@bunda.luanar.mw

Received September 23, 2015; Accepted October 14, 2015; Published October 21, 2015

Citation: Mtethiwa AHN, Bakuza J, Nkwengulila G (2015) Prevalence and Intensity of Schistosomiasis in Communities around Water Reservoirs in Malawi. J Trop Dis 4: 183. doi:10.4172/2329-891X.1000183

Copyright: (c) 2015 Mtethiwa AHN,et al.This is an open-access article distributed under the terms of the Creative Commons Attribution License, which permits unrestricted use, distribution, and reproduction in any medium, provided the original author and source are credited. 
asked to read informed consent forms then sign, whilst the illiterate and participants below 18 years old had the consent form read to them in the presence of an impartial witness and / or guardian after which the participants were asked to thumbprint the consent form. The consent forms were written in both Chichewa and English language which are the most spoken languages in the study areas. Only those who signed or thumbprinted the consent form were allowed to participate in the study.

\section{Study area}

The study was conducted in communities living around water reservoirs at Njala, Ukonde and Mlala reservoirs, located in three different ecological zones in Malawi (Figure 1). The inclusion criteria were that no chemotherapeutical intervention should have been administered in the area at least for the past two years. On the other hand the participant must have been living in the same area for the past 6 months.

\section{Njala water reservoir}

The reservoir is located in Zomba district, near Govala trading centre in the southern region of Malawi between latitudes $15^{\circ} 52^{\prime} 60 \mathrm{~S}$ and longitudes $35^{\circ} 47^{\prime} 60 \mathrm{E}$. It is about $10 \mathrm{~km}$ East of Zomba Township. The size of the reservoir is about 1 hectare and was constructed in the 1970 s by the Malawi Government. The area receives an annual rainfall of $1200-1600 \mathrm{~mm}$ and the average temperature is $26^{\circ} \mathrm{C}$ [12] (Figure 1).

\section{Ukonde water reservoir}

The Ukonde water reservoir is located about 36.5 kilometres south

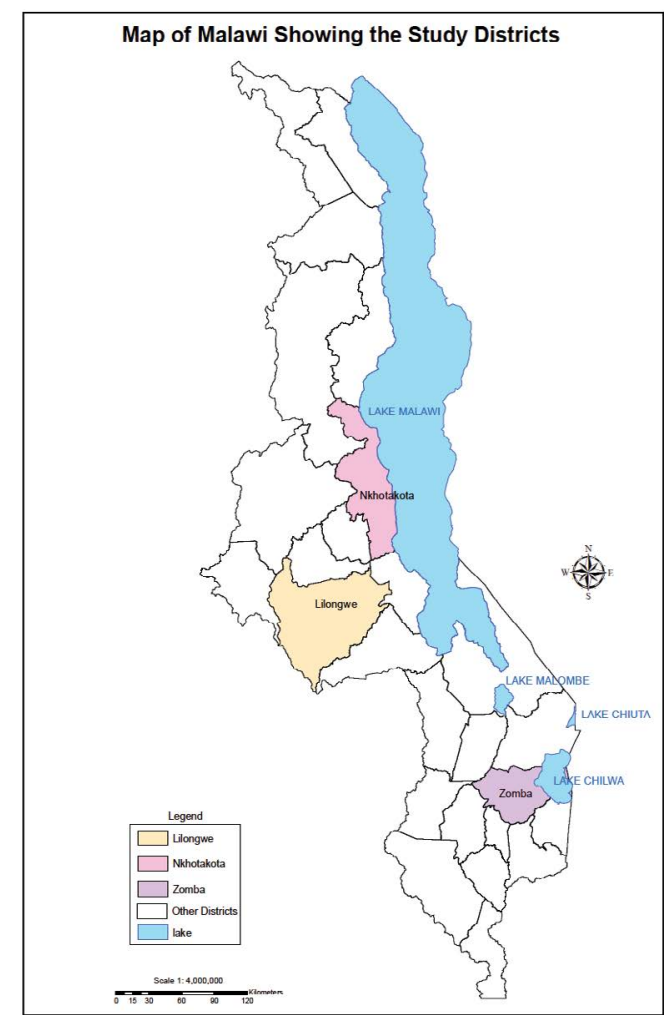

Figure 1: Map of Malawi, showing the location of the three reservoirs; Njala, Ukonde and Mlala. of Lilongwe city, northeast of Kamphata Trading centre in the central region of Malawi. It lies between latitudes $14^{\circ} 35^{\prime} \mathrm{S}$ and longitudes $33^{\circ} 50^{\prime} \mathrm{E}$ and covers an area of about 1 hectare. The Malawi government constructed the water reservoir in the 1970s. The area receives annual rainfall of $800-1200$ and has average temperature of $24^{\circ} \mathrm{C}$ [12], (Figure $1)$.

\section{Mlala water reservoir}

Mlala water reservoir is located in Nkhotakota district, about 70 $\mathrm{km}$ North of Nkhotakota Boma west of Dwangwa Sugar Company in the central region of Malawi. It lies between latitudes $13^{\circ} 0^{\prime}$ and $13^{\circ} 35^{\prime}$ S, and longitudes $33^{\circ} 51^{\prime}$ and $42^{\circ} 25^{\prime} \mathrm{E}$ and is about 2 hectare in size. It is the source of water for agricultural, fishing and domestic activities. The area receives around $1600 \mathrm{~mm} /$ annual rainfall with average temperature of $27^{\circ} \mathrm{C}$ [12], (Figure 1).

\section{Study design and sampling protocol}

This was a cross-sectional study conducted during the rainy and dry seasons. Sample size was calculated using single population proportion formula, by considering the level of significances at $5 \%$, a national schistosomiasis prevalence of $50 \%$ and $5 \%$ marginal error [13]. At least 250 individuals were recruited in each study area and season. The sample size was estimated with consideration of WHO recommendations of a minimum of 200-250 individuals per ecological zone to be recruited in an epidemiological study [14,15]. The study population comprised pre-school children, school children as well as adults with age ranging from 1 to 78 years. The participants were organised in age groups of 1-5, 6-15, 16-19, 20-29, 30-39, 40-49, 5059 and $\geq 60$ years. The number of participants in each age group was estimated in accordance to population distribution by age in each of the study areas as provided in 2008 Malawi population census report [16]. In each age group, a random systematic sampling system was used to identify individuals to be included in the study where every third person was selected to participate.

\section{Sample collection and analysis}

Data on prevalence and infection intensity were obtained through microscopic examination of urine and stools for schistosome eggs. The urine and stools samples were collected for two consecutive days from all individuals who had consented to participate in the study.

\section{Stool examination}

The Kato-Katz faecal examination technique was used to examine stools for Schistosoma mansoni eggs. All selected individuals were firstly registered and assigned a number as their identification. They were later provided with a well-labeled bottle for stool sample after recording their demographic data. The participants were then provided with a full page of an old newspaper, (onto which to defecate), a wooden spatula (for scooping off stool) and a black plastic sheet of about $10 \mathrm{~cm}$ by $10 \mathrm{~cm}$ (for wrapping the scooped stool). Participants were advised to defecate on the newspaper provided. The use of newspaper ensured that the stool sample does not mix with sand and soil, which would make its processing tedious, besides, it ensured easy and convenient disposal of the stool into the latrine. Using the wooden spatula provided, they scooped about $10 \mathrm{~g}$ of stool on to the black plastic sheet of paper provided, wrap it and put it in the bottle provided. They were also advised to dispose of the remaining stool into the latrine and bring the stool sample to laboratory for examination. At the examination centre, a Kato-Katz technique was conducted according to Swiss Tropical Institute $[17,18]$. The eggs found in the stools were enumerated and 
multiplied by 24.1 to convert them into counts per gram. Infection intensity was determined by using the number of eggs per gram (epg) of stool procedure and categorized as: light (1-100 epg), moderate (101399 epg), heavy (400-1000 epg) and very heavy (>1000 epg) [19,20]. For each stool sample brought by a participant, two samples were prepared out of it and examined [18].

\section{Examination of urine samples}

All the selected participants were provided with well-labelled 50 $\mathrm{ml}$ urine bottles. They were then asked to fill half of it (about $25 \mathrm{ml}$ ) with terminally void urine sample. The samples were collected between 10:00 and 14:00 hours as the excretion of S. haematobium eggs follows a circadian rhythm, which peaks around noon [21]. At the examination centre, each urine sample was well mixed before a $10 \mathrm{ml}$ sample was drawn out of it. The samples were then centrifuged at $1000 \mathrm{rpm}$ for 2 minutes and the contents were then allowed to sediment for 10 minutes according to Cheesebrough [22]. Later the supernatant was discarded and the sediments were placed on slide, covered with a slide, mounted on to a compound microscope and examined for urogenital schistosomiasis eggs using X10 and X40 objectives. The number of eggs seen was expressed as eggs / $10 \mathrm{ml}$ urine. The results from urine analysis were used to determine the prevalence of urogenital schistosomiasis as well as infection intensity. The intensity was determined as the number of eggs per individual expressed as negative (0 egg / $10 \mathrm{ml}$ urine), light (1- 49 eggs / $10 \mathrm{ml}$ urine) and heavy ( $\geq 50$ eggs/10 $\mathrm{ml}$ urine) [1].

\section{Data analysis}

Data were analyzed using IBM SPSS for Mackintosh version 22.0 (Armonk, NY: IBM Corp.). Descriptive statistics was used to determine prevalence and frequencies. Bivariate analysis was used to assess the association between schistosomiasis prevalence and age, proximity to the reservoir, seasons and study area. One way ANOVA was used to assess significance of schistosomiasis prevalence and intensity between different demographic and ecological characteristics.

\section{Results}

A total of 1594 individuals aged from 1 to 78 years participated in the study. Whilst all individuals provided urine samples, only 1509 provided stool samples. The proportion of participants in each characteristic in the study is as in Figure 2. The age group of 6-15 years old had a highest representation whilst the age group of 60 years and above was the least represented age group. Similarly, the highest number of participants came from the community closest to the reservoirs $(0-2$ $\mathrm{km}$ ) and the lowest from the community furthest from the reservoir (> $5 \mathrm{~km}$ ). All the three reservoirs had almost the same representation. A total of 71 individuals (4.5\%) did not return stool samples. Despite the noncompliance, the required sample size was achieved in each category hence the data analysis and interpretation was not affected.

\section{Prevalence of schistosomiasis}

The overall (pooled data for S. haematobium and S. mansoni) prevalence of schistosomiasis was $47.4 \%$. The prevalence of $S$. haematobium alone was $51.2 \%$ while that of S. mansoni was $9.5 \%$. The highest prevalence was $58.5 \%$ recorded in the dry season for $S$. haematobium and the lowest was $5.7 \%$ recorded in the age group of $\geq$ 60 years age group for $S$. mansoni (Figure 3). The prevalence of the dry season $(58.5 \%)$ was significantly higher than that of the rainy season $36.6 \%)(\mathrm{P}=0.00)$. The prevalence of the areas $>5 \mathrm{~km}$ from the reservoirs was significantly lower than that $1-2 \mathrm{~km}$ to the reservoir $(\mathrm{P}=0.036)$. There was no significant difference in prevalence of schistosomiasis

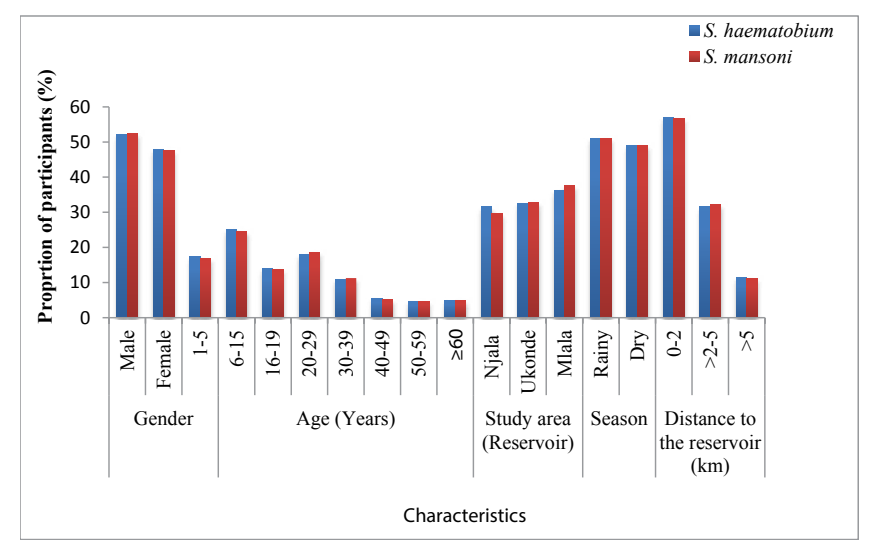

Figure 2: Proportion of participants in each demographic characteristic of the study $(n=1594)$.

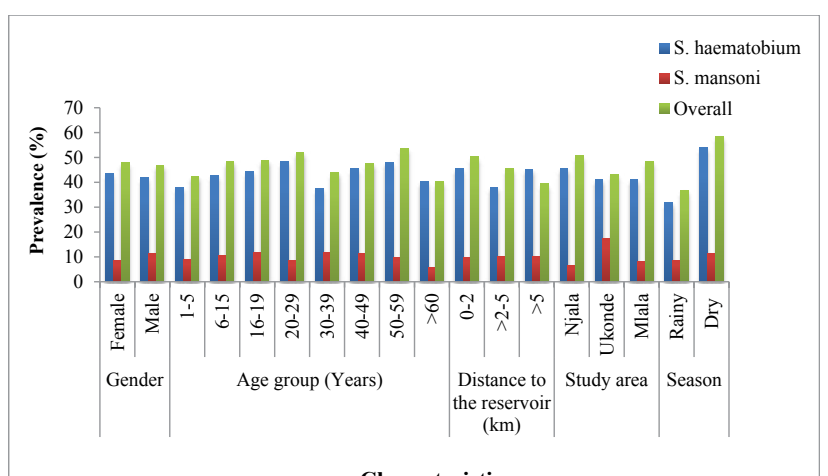

Characteristics

Figure 3: Prevalence of schistosomiasis in respective demographic and ecological characteristics of the study areas.

between males and females $(\mathrm{P}=0.76)$ and the prevalence was not significantly different among different age groups $(\mathrm{P}=0.29)$. However, at Njala and Ukonde reservoirs, the highest prevalence was recorded in the 6 - 15 years age group and the lowest was recorded in the age group of $\geq 60$ years. At Mlala, the highest prevalence was recorded in the age group of 20-29 years and like at Njala, the lowest was recorded in the age group of $\geq 60$ years. Furthermore, the prevalence of $S$. haematobium at Njala reservoir was significantly higher than at Ukonde and Njala reservoirs $(\mathrm{P}=043)$. Prevalence of $S$. mansoni was significantly higher at Ukonde than at Njala and Mlala reservoirs $(\mathrm{P}=0.037)$ (Figure 3).

\section{Infection intensity for S. mansoni}

There were no heavy (400-1000 epg) and very heavy (>1000 epg) cases recorded at all the three reservoirs. Furthermore, there were no moderate (101-399 epg) cases recorded for the age group of $\geq 50$ years. The number of eggs in all individuals examined ranged from 24 to $360 \mathrm{epg}$. The infection intensity of 6-15 years age group was significantly higher than that of the rest of the age groups $(\mathrm{P}=0.03)$. Infection intensity of the males was significantly higher than that of females $(\mathrm{P}=0.04)$. Furthermore, infection intensity of those closer to the reservoirs (1-2 km) was significantly higher than that of those furthest from the reservoir $(>5 \mathrm{~km})(\mathrm{P}=0.02)$ (Table 1$)$. Infection intensity for the dry season was significantly higher than that of the rainy season $(\mathrm{P}=0.03)$. Similar pattern of significantly higher infection intensity in the dry season than the rainy season was recorded at Njala $(\mathrm{P}=0.00)$, 
Ukonde $(\mathrm{P}=0.01)$ and Mlala reservoirs $(\mathrm{P}=0.00)$ (Table 2).

\section{Infection intensity for S. haematobium}

Infection intensity at Njala reservoir was significantly higher than that at Ukonde reservoir $(\mathrm{P}=0.03)$. Infection intensity in communities closer to the reservoir $(1-2 \mathrm{~km})$ was significantly higher than that of communities furthest from the reservoir $(\mathrm{P}=0.04)$. In addition, infection intensity of 6-15 years age group was significantly higher than the other age groups $(\mathrm{P}=0.047)$. Infection intensity for the dry season was significantly higher than that of the rainy season $(\mathrm{P}=0.03)$. It was also found that infection intensity was significantly in dry season than the rainy season at Njala reservoir $(\mathrm{P}=0.00)$, Ukonde reservoir $(\mathrm{P}=0.02)$ and Mlala reservoir $(0.00)$.

\section{Discussion}

\section{Prevalence of schistosomiasis}

The present study found an overall prevalence of $47.4 \%$ against a national prevalence of $50 \%$ which was determined about 15 years ago [6]. Considering that over the years there have been a number of chemotherapeutical interventions on the disease, the national prevalence was expected to be lower. The findings of the present study therefore imply that schistosomiasis is still highly prevalent in Malawi and the water reservoirs are endemic areas. Besides, these findings imply that the water reservoirs in Malawi are contaminated with infected fecal and urine matter. Steinmann, Keiser [3] also reported a high schistosomiasis infection in communities around water reservoirs. Comparatively, the prevalence of schistosomiasis in the present study was lower than that found at other water bodies, such as those along Lake Malawi [23]. The differences could partly be attributed to differences in the selection of participants and methods for determination of schistosomiasis. The

\begin{tabular}{|c|c|c|c|c|c|}
\hline \multirow[b]{2}{*}{ Variable } & \multirow{2}{*}{$\begin{array}{l}\text { No. of } \\
\text { respondents }\end{array}$} & \multicolumn{2}{|c|}{ Prevalence (\%) } & \multirow{2}{*}{$\begin{array}{l}\text { Number of } \\
\text { eggs (range) } \\
\text { epg }\end{array}$} & \multirow[b]{2}{*}{$X^{2}(P<0.05)$} \\
\hline & & \begin{tabular}{|l|} 
Light \\
infection
\end{tabular} & $\begin{array}{l}\text { Moderate } \\
\text { infection }\end{array}$ & & \\
\hline \multicolumn{6}{|l|}{ Gender } \\
\hline Male & 792 & 35.5 & 6.6 & $290.7(24-360$ & \multirow{2}{*}{$19.3(0.052)$} \\
\hline Female & 717 & 36.7 & 7 & $224.2(24-316)$ & \\
\hline \multicolumn{6}{|c|}{ Age (Years) } \\
\hline $0-5$ & 256 & 8.6 & 0.4 & $76.3(24-240)$ & \multirow{8}{*}{$24.5(0.03)$} \\
\hline 6-15 & 371 & 9.7 & 0.8 & $129.0(24-360)$ & \\
\hline $16-19$ & 207 & 10.1 & 1.4 & $76.9(24-240)$ & \\
\hline $20-29$ & 282 & 8.2 & 0.4 & $69(24-360)$ & \\
\hline $30-39$ & 170 & 9.4 & 2.4 & & \\
\hline $40-49$ & 79 & 10.1 & 1.3 & $28.6(24-240)$ & \\
\hline $50-59$ & 71 & 9.9 & 0 & $16.2(48-72)$ & \\
\hline$>60$ & 73 & 6.8 & 0 & $13.3(48-96)$ & \\
\hline \multicolumn{6}{|l|}{ Site } \\
\hline Njala & 860 & 9.4 & 0.7 & $148.8(24-316$ & \multirow[b]{3}{*}{$13.03(0.04)$} \\
\hline Ukonde & 475 & 10.9 & 0.8 & $194.7(24-316$ & \\
\hline Mlala & 174 & 7.4 & 1.1 & $171.5(24-360)$ & \\
\hline \multicolumn{6}{|c|}{ Proximity to the reservoir (km) } \\
\hline $0-2$ & 446 & 8.6 & 1.2 & $314.0(24-360)$ & \multirow[b]{3}{*}{$36.6(0.02)$} \\
\hline$>2-5$ & 496 & 9.9 & 0.4 & $156.9(48-292)$ & \\
\hline$>5$ & 567 & 9.1 & 0.9 & $49.09(24-99)$ & \\
\hline \multicolumn{6}{|l|}{ Season } \\
\hline Rainy & 475 & 7.3 & 1.3 & $224.4(24-360)$ & \multirow{2}{*}{$30.2(0.03)$} \\
\hline Dry & 174 & 11 & 0.4 & $290.6(24-360)$ & \\
\hline
\end{tabular}

Table 1: Egg count and prevalence (Light and moderate infection prevalence) of $\mathrm{S}$. mansoni in the study areas (Pooled data)

\begin{tabular}{|c|c|c|c|c|c|}
\hline \multirow{2}{*}{ Variable } & \multirow[t]{2}{*}{$\begin{array}{l}\text { No of } \\
\text { respondents }\end{array}$} & \multicolumn{2}{|c|}{ Prevalence (\%) } & \multirow{2}{*}{$\begin{array}{l}\text { Number of } \\
\text { eggs (range) } \\
\text { Egg/10ml } \\
\text { urine }\end{array}$} & \multirow[t]{2}{*}{$X^{2}(P<0.05)$} \\
\hline & & $\begin{array}{l}\text { Light } \\
\text { infection }\end{array}$ & $\begin{array}{l}\text { Heavy } \\
\text { infection }\end{array}$ & & \\
\hline \multicolumn{5}{|l|}{ Gender } & \\
\hline Male & 763 & 36.7 & 7 & $32.7(4-192)$ & \multirow{2}{*}{$\begin{array}{l}14.02 \\
(0.67)\end{array}$} \\
\hline Female & 831 & 35.5 & 6.6 & $13.3(4-178)$ & \\
\hline \multicolumn{5}{|c|}{ Age (Years) } & \\
\hline $1-5$ & 275 & 31.3 & 7.3 & $37.7(4-164$ & \multirow{8}{*}{$\begin{array}{l}32.06 \\
(0.047)\end{array}$} \\
\hline $6-15$ & 399 & 35.5 & 7 & $63.3(4-188)$ & \\
\hline $16-19$ & 221 & 40.3 & 3.6 & $35.3(6-178)$ & \\
\hline $20-29$ & 287 & 40.1 & 8.7 & $42.6(6-192)$ & \\
\hline $30-39$ & 176 & 30.7 & 6.8 & $16.6(4-164)$ & \\
\hline $40-49$ & 88 & 38.6 & 6.8 & $8.2(10-126)$ & \\
\hline $50-59$ & 71 & 39.4 & 7.0 & $5.4(12-98)$ & \\
\hline$>60$ & 77 & 35.1 & 5.2 & $4.6(4-78)$ & \\
\hline \multicolumn{5}{|c|}{ Study area } & \\
\hline Njala & 502 & 37.8 & 8.0 & $36.2(4-192)$ & \multirow{3}{*}{$\begin{array}{l}27.04 \\
(0.042)\end{array}$} \\
\hline Ukonde & 516 & 33.3 & 4.3 & $16.3(4-164)$ & \\
\hline Mlala & 576 & 37.2 & 8.3 & $34.5(4-188)$ & \\
\hline \multicolumn{5}{|c|}{ Distance from the reservoir $(\mathrm{km})$} & \multirow{4}{*}{$\begin{array}{l}42.12 \\
(0.04)\end{array}$} \\
\hline $0-2$ & 902 & 38.8 & 6.9 & $33.71(4-192)$ & \\
\hline$>2-5$ & 514 & 34.0 & 7.2 & $14(4-168)$ & \\
\hline$>5$ & 178 & 28.7 & 5.1 & $5.95(6-148)$ & \\
\hline \multicolumn{5}{|l|}{ Season } & \multirow{3}{*}{$\begin{array}{l}37.01 \\
(0.03)\end{array}$} \\
\hline Rainy & 811 & 23.9 & 8.1 & $15.7(4-192)$ & \\
\hline Dry & 783 & 48.8 & 5.2 & $42.01(4-176)$ & \\
\hline
\end{tabular}

Table 2: Egg counts and prevalence (Light and heavy infection) of S. haematobium infection in the study area (Pooled data)

study at the Lake purposely selected only school children [10,24], while the present study examined all age groups from 1 to 78 years. Additionally, conventional microscopy was used whilst the other studies enlisted serological methods [24]. These contributed to the already existing differences in ecology, attitudes, water contact behavior and practices between the Lake Malawi communities and the reservoir communities, the subjects of the present study. However, the present study has provided sufficient evidence that dams in Malawi play a major role in transmission of schistosomiasis in Malawi and that all age groups are at risk. The findings of the present study have also confirmed that in Malawi, S. haematobium is more prevalent (51.2\%) than S. mansoni (9.5\%) as reported in Bowie, Purcell [7]. These differences in prevalence of the two Schistosoma species can be attributed to the variation in the abundance of their respective snail intermediate hosts. Studies in Lake 
Malawi have found more Bulinus snails than Biomphalaria [10]. A similar situation of more Bulinus snails than Biomphalaria snail may be present in the water reservoirs, translating to more S. haematobium than S. mansoni schistosomiasis infection and prevalence. The prevalence of schistosomiasis was significantly higher in the dry season $(58.5 \%)$ than in the rainy season (36.6\%). This could be a reflection of increased fecal contamination of the water bodies and increased water contact frequency by the communities in the dry season. During the dry season, water is generally highly scarce, because many water points dry up, such that most people would heavily depend on the reservoirs. As such, most activities that require water are conducted at the reservoir. This, in turn, increases the water contact frequency during the dry season resulting to high contraction of schistosomiasis. Anto, Asoala [25] reported similar findings in Ghana. Additionally, dry season presents conducive environment for buildup of snail populations [26]. This is because the water temperature, the water levels and water currents are more conducive than during the rainy season when the rains are heavy and wash away many of the snails [27,28]. Similar patterns of higher schistosomiasis prevalence in the dry season than the rainy season have also been reported in [25-29].

The prevalence of schistosomiasis was significantly higher in communities closer to the reservoir $(0-2 \mathrm{~km})$ than those furthest $(>5$ $\mathrm{km})$. This is an indication that the frequency of visits to the reservoirs by individuals from distant places $(>5 \mathrm{~km})$ may have been lower hence the lower prevalence. Assuming all communities solely depend on the reservoir for their water needs, communities proximal to the reservoir may frequent the water body than those furthest from the reservoir. Similar findings of higher prevalence in areas proximal to the reservoir have been reported by [30,31] and has been attributed to increased water contact frequency by communities closer to the reservoir. The higher the water contact frequency, the more the chance of getting infected by schistosomiasis. Significantly higher prevalence of schistosomiasis was found in Njala reservoir than at Ukonde and Mlala reservoirs. These three reservoirs lied in three different areas and had differences in rainfall distribution average temperatures. It is therefore assumed that these variations in ecological characteristics were responsible for the differences in schistosomiasis prevalence. Njala and Mlala reservoirs, which receive more rainfall with a longer season, provided adequate water and more favourable environment for snail intermediate host hence a higher prevalence. Equally important in facilitating transmission, are the communities' occupation. It was observed that communities around Njala reservoir were mostly irrigation rice farmers, unlike those in Mlala and Ukonde. With this type of occupation, water contact frequency is higher, hence increased chances of contracting schistosomiasis. The findings of the present study corroborate observations by [3-32] who, in their studies, reported a higher prevalence of schistosomiasis in irrigational reservoirs than in non-irrigational reservoir. The present study found no significant difference in prevalence among different age groups although school children were among the highly infected (Figure 1). These findings imply that, in the present study, all water reservoir communities may have similar water contact behavior regardless of age. The findings further mean that individuals around communal water have the same risk regardless of age. However, studies by [33-35] found significant differences between different ages. However, their studies used school children whilst the present study used participants with ages from 1 to 78 years.

\section{Infection intensity for S. mansoni and S. haematobium}

Whilst prevalence of schistosomiasis did not show any significant difference on age, infection intensity of the 6-15 years age group was significantly higher than the other age groups. The findings can be attributed to high worm burden and high fecundity rate of the worms in children, due to a lower immunity [36,37]. Adults might have had infection for longer period. The prolonged infection in the elderly leads to development of pseudo-tubercles and pseudo-papillae in the mucosa and sub-mucosa of the colon which traps most of the [20,23,38]. Similar findings of decreasing egg counts with increasing age were also reported by [15]. Children below 5 years of age gave also startling results of infection intensity as $8.6 \%$ of them had egg loads of 101 to 360 epg (Table 1). This was unexpected considering that these are kids at tender age. However, the results imply that children begin to accompany their mothers as well as siblings to the reservoir at very tender age as also observed by [36].

\section{Conclusion}

From the findings of this study it can be concluded that water reservoirs in Malawi are highly infested with Schistosoma cercariae and the reservoir communities are at risk. Proximity to the water reservoir, study area and seasons are the factors that expose the reservoir communities to higher chances of contracting schistosomiasis. We recommend annual Mass Drug Administration (MDA), as the prevalence found is within the $\geq 50 \%$ WHO recommended threshold for MDA. Besides, we recommend health education to the communities on transmission dynamics and prevention of schistosomiasis.

\section{Study Limitation}

The study used microscopy to examine the urine and stool samples, for Schistosoma eggs, which is less sensitive than serological methods. As such, the prevalence found in the present study could be slightly lower. Due to limitation in financial resources, three water reservoirs communities were studied out of the about 750 water reservoirs in Malawi. However, the locations of the water reservoirs represented the major ecological zones in Malawi.

\section{Acknowledgements}

This work was supported by the Consortium for Advanced Research and Training in Africa (CARTA). CARTA is jointly led by the African Population and Health Research Center and the University of the Witwatersrand and funded by the Wellcome Trust (UK) (Grant No: 087547/Z/08/Z), the Department for International Development (DfID) under the Development Partnerships in Higher Education (DelPHE), the Carnegie Corporation of New York (Grant No: B 8606), the Ford Foundation (Grant No: 1100-0399), Google.Org (Grant No: 191994), Sida (Grant No: 54100029) and MacArthur Foundation Grant No: 10-95915-000-INP”. We sincerely appreciate their support and the Lilongwe University of Agriculture and Natural Resources (LUANAR) for co-funding the research from which this work emanates.

\section{References}

1. Olveda DU, Li Y, Olveda RM, Lam AK, Chau TN, et al. (2013) Bilharzia: Pathology, Diagnosis, Management and Control. Trop Med Surg 1.

2. Coeli R, Baba EH, Araujo N, Coelho PM, Oliveira G (2013) Praziquantel treatment decreases Schistosoma mansoni genetic diversity in experimental infections. PLoS Negl Trop Dis 7: e2596.

3. Steinmann P, Keiser J, Bos R, Tanner M, Utzinger J (2006) Schistosomiasis and water resources development: systematic review, meta-analysis, and estimates of people at risk. Lancet Infect Dis 6: 411-425

4. Enk MJ, Lima AC, Barros Hda S, Massara CL, Coelho PM, et al. (2010) Factors related to transmission of and infection with Schistosoma mansoni in a village in the South-eastern Region of Brazil. Mem Inst Oswaldo Cruz 105: 570-577.

5. Kapito-Tembo AP, Mwapasa V, Meshnick SR, Samanyika Y, Banda D, et al (2009) Prevalence distribution and risk factors for Schistosoma hematobium infection among school children in Blantyre, Malawi. PLoS Negl Trop Dis 3 : 
Citation: Mtethiwa A HN, Bakuza J, Nkwengulila G (2015) Prevalence and Intensity of Schistosomiasis in Communities around Water Reservoirs in Malawi. J Trop Dis 4: 183. doi:10.4172/2329-891X.1000183

Page 6 of 6

e361.

6. GoM (2001) Schistosomiasis Control Programme - Community Health Surveillance Unit (1997-2001): Lakeshore Schistosomiasis Control Project. Ministry of Health and Population, Lilongwe.

7. Bowie C, Purcell B, Shaba B, Makaula P, Perez M (2004) A national survey of the prevalence of schistosomiasis and soil transmitted helminths in Malawi. BMC Infect Dis 4: 49 .

8. Msyamboza K, Ngwira B, Banda R, Mkwanda S, Brabin B (2010) Sentinel surveillance of Lymphatic filariasis, Schistosomiasis, Soil transmitted helminths and Malaria in rural southern Malawi. Malawi Medical Journal 22: 12-14.

9. Makaula P, Sadalaki JR, Muula AS, Kayuni S, Jemu S, et al. (2014) Schistosomiasis in Malawi: a systematic review. Parasit Vectors 7: 570.

10. Madsen H, Bloch P, Makaula P, Phiri H, Furu P, et al. (2011) Schistosomiasis in Lake MalaÅni villages. Ecohealth 8: 163-176.

11. GoM (2004) Report on Malawi National Consultative meeting on World Commission on Dams (WCD) report: Dams and Development: a new framework for decision making. Ministry of Water Development, Lilongwe.

12. Esser K, Øygard R, Chibwana C, Blackie M (2005) Opportunities for Norwegian Support to Agricultural Development in Malawi.

13. Alemu M, Hailu A, Bugssa G (2014) Prevalence of intestinal schistosomiasis and soil transmitted helminthiasis among primary school children in Umolante district, South Ethiopia. Clinical Medicine Research 6: 174-180.

14. Lorenzo S, Montresor A, Crompton DWT, Hall A, Bundy DAP (1998) Guidelines for evaluation of Soil transmitted helminths and schistosomiasis at community level. World Health Organisation, Geneva.

15. Agi PI, Okafor EJ (2005) The Epidemiology of Schistosoma haematobium in Odau Community in the Niger Delta Area of Nigeria. J Appl Sci Environ Mgt 3: $37-43$.

16. GoM-NSO (2008) Population and housing census. Ministry of Economic Planning and Development, National Statistical Office, Malawi.

17. Swiss Tropical Institute (2005) Kato-katz helminths eggs. Swis Tropical institute, Basel, Switzerland.

18. Krauth SJ, Coulibaly JT, Knopp S, Traoré M, N'Goran EK, et al. (2012) An in-depth analysis of a piece of shit: distribution of Schistosoma mansoni and hookworm eggs in human stool. PLoS Negl Trop Dis 6: e1969.

19. Katz N, Chaves A, Pellegrino J (1972) A simple device for quantitative stool thick-smear technique in Schistosomiasis mansoni. Rev Inst Med Trop Sao Paulo 14: 397-400.

20. Muller R (2002) Worms and human disease. (2ndedn) CABI Publishing, New York.

21. Doehring E, Vester U, Ehrich JH, Feldmeier H (1985) Circadian variation of ova excretion, proteinuria, hematuria, and leukocyturia in urinary schistosomiasis. Kidney Int 27: 667-671.

22. Cheesebrough M (2005) District laboratory practice in Tropical countries. $\left(2^{\text {nd }} e d n\right)$ Tropical Health Technology, London.
23. Ross AG, Bartley PB, Sleigh AC, Olds GR, Li Y, et al. (2002) Schistosomiasis N Engl J Med 346: 1212-1220.

24. Stauffer JJ, Madsen M (2012) Schistosomiasis in Lake Malawi and the Potential Use of Indigenous Fish for Biological Control, Schistosomiasis.

25. Anto F, Asoala V, Adjuik M, Anyorigiya T, Oduro A, et al. (2013) Water Contact Activities and Prevalence of Schistosomiasis Infection among School-age Children in Communities along an Irrigation Scheme in Rural Northern Ghana. J Bacteriol Parasitol 4: 1-10.

26. Dida GO, Gelder FB2, Anyona DN3, Matano AS4, Abuom PO3, et al. (2014) Distribution and abundance of schistosomiasis and fascioliasis host snails along the Mara River in Kenya and Tanzania. Infect Ecol Epidemiol 4.

27. Madsen H, Bloch P, Phiri H, Kristensen TK, Furu P (2001) Bulinus nyassanus is an intermediate host for Schistosoma haematobium in Lake Malawi. Ann Trop Med Parasitol 95: 353-360.

28. Slootweg RE, Van Rign JA, Schijndel MJ, Djkstra M, Colenbrander AC (1993) A longitudinal study of snail intermediate hosts of trematode parasite in Benie valley in North Cameroon. Journal of Medical and Applied Malacology 5: 45-49.

29. Ivoke N, Ivoke ON, Nwani CD, Ekeh FN, Asogwa CN, et al. (2014) Prevalence and transmission dynamics of Schistosoma haematobium infection in a rural community of south- western Ebonyi State, Nigeria. Tropical Biomedicine 31 77-88.

30. Zakhary K (2010) Factors Affecting the Prevalence of Schistosomiasis in the Volta Region of Ghana. McGill Journal of Medicine 2: 93-101.

31. Isa Y, Modu AM, R. S. Naphtali RS (2015) A Study on Schistosomiasis in Three Communities along Lake Alau, Konduga Local Government Area, Borno State, Nigeria. The International Journal of Science \& Technowledge 2: 23-79.

32. Yamana T (2004) The impacts of dams and reservoirs on Public Health Massachusetts, New York.

33. Mutapi F, Burchmore R, Mduluza T, Midzi N, Turner CM, et al. (2008) Agerelated and infection intensity-related shifts in antibody recognition of defined protein antigens in a schistosome-exposed population. J Infect Dis 198: 167175.

34. Deribe K, Eldaw A, Hadziabduli S, Kailie E, Omer MD, et al. (2011) High prevalence of urinary schistosomiasis in two communities in South Darfur: implication for interventions. Parasit Vectors 4: 14.

35. Mazigo H, Waihenya R, Mkoji G, Zinga M, Ambrose E, et al. (2010) Intestina Schistosomiasis: Prevalence, knowledge, attitude and practice among children in an endemic area of North Western Tanzania. J Rural Trop Public Health 9: 53-60.

36. Chinwe E, Agi P (2012) Urogenital Schistosomiasis among Fulani Pastoralists in Rivers State. International Journal of tropical Disease \& Health 12: 12781286.

37. Behnke JM (2005) Parasites, immunity and pathology: the consequences of parasitic infection in mammals. Taylor \& Francis, London.

38. Jordan P, Webbe G, Sturrock RF (1993) Human Schistosomiasis. Wallingford: CAB International 1- 465 . 